\begin{tabular}{|c|c|c|}
\hline Case Reports in & \multicolumn{2}{|c|}{ Case Rep Gastroenterol 2015;9:1-6 } \\
\hline Gastroenterology & $\begin{array}{l}\text { DOI: 10.1159/000371541 } \\
\text { Publisned online: January 14, } 2015\end{array}$ & $\begin{array}{l}\text { (c) } 2015 \text { S. Karger AG, Basel } \\
1662-0631 / 15 / 0091-0001 \$ 39.50 / 0 \\
\text { www.karger.com/crg }\end{array}$ \\
\hline & \multicolumn{2}{|c|}{$\begin{array}{l}\text { This is an Open Access article licensed under the terms of the Creative Commons } \\
\text { Attribution-NonCommercial } 3.0 \text { Unported license (CC BY-NC) (www.karger.com/OA- } \\
\text { license), applicable to the online version of the article only. Distribution permitted for non- } \\
\text { commercial purposes only. }\end{array}$} \\
\hline
\end{tabular}

\title{
Necrotizing Encephalitis Caused by Disseminated Aspergillus Infection after Orthotopic Liver Transplantation
}

\author{
Luis E. Barrera-Herrera ${ }^{a} \quad$ Alonso Vera ${ }^{b, c}$ Johanna Álvarez ${ }^{a, c}$ \\ Rocio Lopez ${ }^{a, c}$ \\ ${ }^{a}$ Pathology and Clinical Laboratory Department and ${ }^{\mathrm{b}}$ Transplant Service, Fundación \\ Santa Fe de Bogotá University Hospital, and 'School of Medicine, Universidad de los \\ Andes, Bogotá, Colombia
}

\section{Key Words}

Orthotopic liver transplant · Aspergillosis · Necrotizing encephalitis

\begin{abstract}
Liver transplantation is the only available treatment for some patients with end-stage liver disease. Despite reduction in mortality rates due to advances related to surgical techniques, intensive medical management and immunosuppressive therapy, invasive fungal infections remain a serious complication in orthotopic liver transplantation. We report the case of an 18-year-old male diagnosed with autoimmune cirrhosis in 2009 who was assessed and listed for liver transplantation for massive variceal hemorrhage. One year after listing a successful orthotopic liver transplantation was performed. Uneventful early recovery was achieved; however, he developed pulmonary and neurological Aspergillus infection 23 and 40 days after surgery, respectively. Antibiotic therapy with voriconazole and amphotericin was started early, with no major response. Neuroimaging revealed multiple right frontal and right parietal lesions with perilesional edema; surgical management of the brain abscesses was performed. A biopsy with periodic acid-Schiff and Gomori stains revealed areas with mycotic microorganisms morphologically consistent with Aspergillus, later confirmed by culture. The patient developed necrotizing encephalitis secondary to aspergillosis and died. Necrotizing encephalitis as a clinical presentation of Aspergillus infection in an orthotopic liver transplant is not common, and even with adequate management, early diagnosis and prompt antifungal treatment, mortality rates remain high.

(C) 2015 S. Karger AG, Basel
\end{abstract}

KARGER 125/s $\quad \begin{aligned} & \text { Rocio Lopez } \\ & \text { Pathology and Clinical Laboratory Department } \\ & \text { Fundación Santa Fe de Bogotá University Hospital } \\ & \text { Calle } 119 \text { No.7-75, Bogotá 110111 (Colombia) } \\ & \text { E-Mail rolopez@uniandes.edu.co or rocio.lopez@fsfb.org.co }\end{aligned}$


Barrera-Herrera et al.: Necrotizing Encephalitis Caused by Disseminated Aspergillus Infection after Orthotopic Liver Transplantation

\section{Introduction}

Orthotopic liver transplantation is the only definitive therapeutic option for patients with end-stage liver disease. However, invasive fungal infections are an important cause of post-transplantation mortality in solid organ recipients, and their incidence, particularly for candidiasis and aspergillosis, varies from 1.4 to $42 \%$ of cases [1]. In solid organ transplant recipients, disseminated fungal infections by Candida spp. account for $59.0 \%$, by Aspergillus spp. for $24.8 \%$, by Cryptococcus spp. for $7.0 \%$ and by other molds for $5.8 \%$ [2]. Despite prompt diagnosis and early management, mortality due to fungal infections depends on the type of transplant and can range between 3 and 100\% [1, 3]. Fungal infections frequently occur in the first month post transplantation [4], and their incidence differs in frequency and specific etiology according to the type of transplanted organ, procedure and transplantation center [5]. The clinical presentation of fungal infections can range from asymptomatic to disseminated and the clinical presentation of central nervous system infection may be subtle and difficult to diagnose, with life-threatening infections [6].

\section{Case Report}

We report the case of an 18-year-old male diagnosed with autoimmune cirrhosis in 2009 who was assessed and listed for liver transplantation for massive variceal hemorrhage. His past medical history revealed an ostium secundum managed uneventfully with percutaneous Amplatzer 2 years before liver transplantation. Pre-transplantation pharmacological management included propranolol (20 mg t.i.d.), azathioprine (50 mg q.d.), vitamin E (400 IU q.d.) and multivitamin supply. Assessment for transplantation was successfully overcome with no contraindication. Laboratory tests demonstrated leukopenia $4.58 \times 10^{3} / \mu \mathrm{l}$ (normal 5-10 × 103/ $\mathrm{ll}$ ), with lymphocytes $27.14 \%$ (normal 30-40\%), anemia (hemoglobin $12.4 \mathrm{~g} / \mathrm{l}$ [normal 12-16 g/dl], hematocrit 38.5\% [normal 45-54\%]), thrombocytopenia (platelets $45 \times 10^{3} / \mu \mathrm{l}$ [normal 150-450 × 103/ $\mathrm{l}$ ]), alkaline phosphatase $225 \mathrm{U} / \mathrm{l}$ (normal 32-91 U/l), total serum bilirubin $1.64 \mathrm{mg} / \mathrm{dl}$ (normal $0.3-1.9 \mathrm{mg} / \mathrm{dl}$ ), direct bilirubin $0.9 \mathrm{mg} / \mathrm{dl}$, indirect bilirubin $0.74 \mathrm{mg} / \mathrm{dl}$, severity score of CHILD A and MELD 11. Variceal banding was successfully performed.

Previous chest X-rays were normal. However, during surgery the patient experienced desaturation and we immediately performed an X-ray, which detected right superior and inferior lobar atelectasis; the symptoms improved with positive pressure therapy. On-site bronchoscopy found purulent tracheal secretions. On the fifth postoperative day he developed clinical sepsis, needing management at the intensive care unit. Because of increased cholestasis, endoscopic retrograde cholangiopancreatography and biliary stenting were performed; additionally, we performed a cardiothoracic focus search because his clinical past, apart from transesophageal echocardiography, was normal.

A month after liver transplantation, because of persistent tracheal secretions, sputum cultures were taken, finding Aspergillus spp. A thoracic CT scan showed multiple nodes in both lungs, with imaging patterns of tree-in-bud opacities, suggesting pulmonary Aspergillus. Despite fungal treatment including posaconazole, caspofungin, amphotericin B and aciclovir, the patient developed neurological symptoms including left hemiplegia, severe headache and mental status changes. Magnetic resonance imaging of the brain showed multiple right frontal and right parietal lesions with perilesional edema (fig. 1). The patient underwent biopsy of brain lesions under stereotactic guidance. Despite treatment, he developed multiple organ failure and he died 48 days after liver transplantation. 
Barrera-Herrera et al.: Necrotizing Encephalitis Caused by Disseminated Aspergillus Infection after Orthotopic Liver Transplantation

The explanted cirrhotic liver revealed abundant copper deposits (fig. 2a, b). Complementary studies including aldehyde fuchsin and periodic acid-Schiff without diastases revealed areas of hepatic parenchyma with significant deposits of copper and its binding protein, mostly at periseptal location, in some foci a very small amount and in others complete absence, minimum focal intracanalicular cholestasis and no Mallory bodies or major ballooning. These findings together with the clinical suspicion of a metabolic disease were consistent with Wilson's disease; what is striking, however, is the absence of other histologic findings characteristic of this condition in the active state, including Mallory bodies, ballooning and prominent nuclear pseudoinclusions, among others.

Trucut liver biopsy obtained 4 days after transplantation showed a hepatic parenchyma with hepatocanalicular cholestasis from zone 3 to zone 2 and focally in zone 1 . Apoptotic hepatocytes, Kupffer cells with abundant pigment and sinusoidal congestion were also observed. Trichrome staining showed no fibrosis, Kupffer cells with rich resistant periodic acid-Schiff-diastase (PAS-D)-positive material and some intracytoplasmic iron deposits $(+/++++)$. Histochemical study for cytomegalovirus was negative. The described findings corresponded to a mild acute cellular rejection, Banff score 4/9 (portal swelling 2, ductulitis 1 , endotheliitis 1) associated with hepatocanalicular cholestasis.

From the cerebral collection (frontal right abscesses), H\&E and histochemical staining with PAS-D, Ziehl-Neelsen, Gram and Gomori were performed. Fragments of brain parenchyma showed edema, extensive necrosis, neutrophil infiltration in abundant quantity, apoptotic cells and presence of abundant septate hyphae angled at $45^{\circ}$, morphologically compatible with Aspergillus spp. (fig. 2c, d), corroborated by the PAS-D and Gomori stains. The Ziehl-Neelsen and Gram stains were negative for acid-alcohol-resistant bacilli and bacteria, respectively. A diagnosis of necrotizing encephalitis with organisms morphologically compatible with Aspergillus structures was made.

\section{Discussion}

Fungal infections are among the most common complications in transplantation. Candida and Aspergillus account for 70-90\% of all cases [5]. In liver transplantation both organisms explain the vast majority of invasive fungal infections and are considered as a significant cause of morbidity and mortality. When the central nervous system is compromised by an abscess, Aspergillus is the most common etiology and has a tendency to spread to any other organ through hematogenous dissemination [7]; however, these infections usually grow very slowly, making the clinical information decisive for the presumptive diagnosis.

For both bacterial and fungal agents, fever, headache, vomiting and altered sensorium are the presenting symptoms of intracranial abscess, with mortality rates varying between 10 and 15\% [8]. Our patient presented altered state of consciousness, measles, tachycardia and fever 15 days after transplantation. Unfortunately the outcome was consistent with some descriptions that established the patient's neurological status at presentation as a significant predictor of outcome, with an increased mortality rate in those who present with altered mental status and rapid neurological deterioration $[9,10]$.

Despite correct surgical techniques, immunosuppressive therapy and advanced medical treatment, fungal infections remain a significant cause of post-transplantation morbidity and mortality [11]. In case of clinical suspicion of fungal infection, cultures will confirm the infectious agent; however, the sensitivity of fungal cultures is relatively low, thus some authors suggested that measuring Aspergillus antigens such as galactomannan in clinical samples such as plasma, serum, bronchoalveolar lavage fluid or cerebrospinal fluid would be 
Barrera-Herrera et al.: Necrotizing Encephalitis Caused by Disseminated Aspergillus Infection after Orthotopic Liver Transplantation

useful for diagnosis [12]. In our case, suspicion of infection justified the bronchoalveolar lavage that indeed revealed the primary Aspergillus infection.

The current recommendation in cerebral Aspergillus infection includes surgical excision and debridement of the abscess, antifungal therapy and reduction in the immunosuppressive regime after liver transplantation [12]. This last issue was difficult to achieve in our case due to the progressive cholestasis, altered liver function tests and the mild acute cellular rejection proven with the transplant biopsy. Similarly, our patient was not at high risk for fungal infection; antifungal prophylaxis does not reduce overall mortality, and its beneficial effect has been predominantly associated with the reduction of $C$. albicans infection and mortality [13]. It is therefore essential to have in place an effective approach focus in prevention and based on predicted infection risk, including local antimicrobial resistance patterns and surveillance of specific risk factors [14].

\section{Conclusion}

Regardless of adequate surgical techniques and immunosuppressive therapies, this case presents the challenges in diagnosing and treating fungal infections in solid organ transplantation. Even though brain abscesses caused by Aspergillus are not common in orthotopic liver transplantation, we emphasize that in immunocompromised patients who develop mental status changes, seizures or focal neurological findings, despite prompt medical intervention there are predominantly worse outcomes among liver and heart transplant recipients $[2,10]$. Certainly, prospective studies are needed to accurately assess the risk of fungal infections and antifungal prophylaxis prior to transplantation to help informed decisionmaking focus on effective prevention and treatment.

\section{Disclosure Statement}

The authors declare that there is no conflict of interests regarding the publication of this article.

\section{References}

1 Pacholczyk M, Lagiewska B, Lisik W, Wasiak D, Chmura A: Invasive fungal infections following liver transplantation - risk factors, incidence and outcome. Ann Transplant 2011;16:14-16.

-2 Neofytos D, Fishman JA, Horn D, Anaissie E, Chang CH, Olyaei A, Pfaller M, Steinbach WJ, Webster KM, Marr KA: Epidemiology and outcome of invasive fungal infections in solid organ transplant recipients. Transpl Infect Dis 2010;12:220-229.

-3 Shu KH, Ho HC, Wen MC, Wu MJ, Chen CH, Cheng CH, Yu TM, Chuang YW, Huang ST, Tsai SF, Lo YC, Weng SC: Changing pattern of mortality in renal transplant recipients: a single-center, 30 -year experience. Transplant Proc 2014;46:442-444.

4 Shi SH, Lu AW, Shen Y, Jia CK, Wang WL, Xie HY, Zhang M, Liang TB, Zheng SS: Spectrum and risk factors for invasive candidiasis and non-Candida fungal infections after liver transplantation. Chin Med J (Engl) 2008;121:625-630.

5 Pappas PG, Alexander BD, Andes DR, Hadley S, Kauffman CA, Freifeld A, Anaissie EJ, Brumble LM, Herwaldt L, Ito J, Kontoyiannis DP, Lyon GM, Marr KA, Morrison VA, Park BJ, Patterson TF, Perl TM, Oster RA, Schuster MG, Walker R, Walsh TJ, Wannemuehler KA, Chiller TM: Invasive fungal infections among organ transplant recipients: results of the Transplant-Associated Infection Surveillance Network (TRANSNET). Clin Infect Dis 2010;50:1101-1111.

-6 Singh N, Arnow PM, Bonham A, Dominguez E, Paterson DL, Pankey GA, Wagener MM, Yu VL: Invasive aspergillosis in liver transplant recipients in the 1990s. Transplantation 1997;64:716-720. 
Barrera-Herrera et al.: Necrotizing Encephalitis Caused by Disseminated Aspergillus Infection after Orthotopic Liver Transplantation

7 Torre-Cisneros J, Lopez OL, Kusne S, Martinez AJ, Starzl TE, Simmons RL, Martin M: CNS aspergillosis in organ transplantation: a clinicopathological study. J Neurol Neurosurg Psychiatry 1993;56:188-193.

8 Choudhury N, Khan AB, Tzvetanov I, Garcia-Roca R, Oberholzer J, Benedetti E, Jeon H: Cerebellar abscess caused by Listeria monocytogenes in a liver transplant patient. Transpl Infect Dis 2013;15:E224-E228.

-9 Mampalam TJ, Rosenblum ML: Trends in the management of bacterial brain abscesses: a review of 102 cases over 17 years. Neurosurgery 1988;23:451-458.

10 Feltracco P, Barbieri S, Furnari M, Milevoj M, Rizzi S, Galligioni H, Salvaterra F, Zanus G, Cillo U, Ori C: Central nervous system infectious complications early after liver transplantation. Transplant Proc 2010;42: 1216-1222.

-11 Brizendine KD, Vishin S, Baddley JW: Antifungal prophylaxis in solid organ transplant recipients. Expert Rev Anti Infect Ther 2011;9:571-581.

12 Singh N, Husain S; AST Infectious Diseases Community of Practice: Invasive aspergillosis in solid organ transplant recipients. Am J Transplant 2009;9(suppl 4):S180-S191.

13 Cruciani M, Mengoli C, Malena M, Bosco O, Serpelloni G, Grossi P: Antifungal prophylaxis in liver transplant patients: a systematic review and meta-analysis. Liver Transpl 2006;12:850-858.

14 Romero FA, Razonable RR: Infections in liver transplant recipients. World J Hepatol 2011;3:83-92.

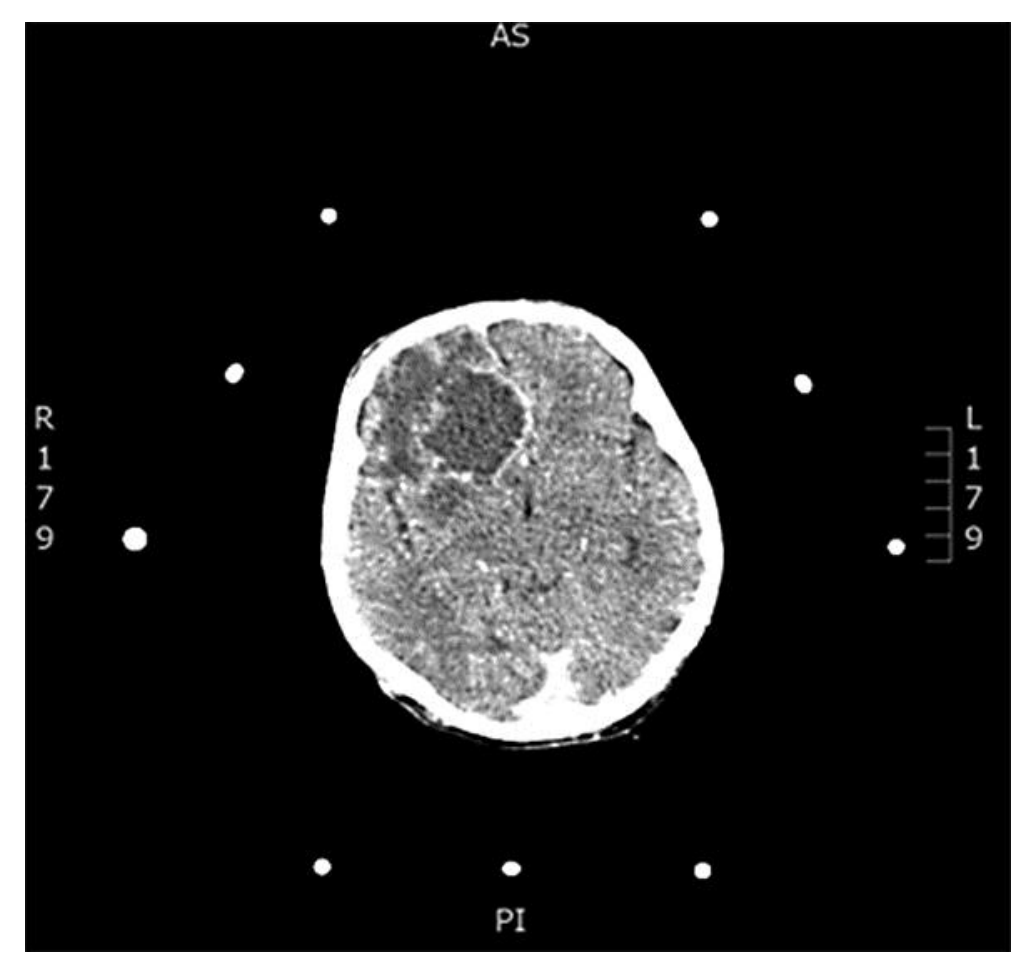

Fig. 1. CT scan showing multiple right frontal lesions. 


\begin{tabular}{|c|c|c|}
\hline \multirow{2}{*}{$\begin{array}{l}\text { Case Reports in } \\
\text { Gastroenterology }\end{array}$} & \multicolumn{2}{|c|}{ Case Rep Gastroenterol 2015;9:1-6 } \\
\hline & DOI: 10.1159/000371541 & $\begin{array}{l}\text { (C) } 2015 \text { S. Karger AG, Basel } \\
\text { www.karger.com/crg }\end{array}$ \\
\hline
\end{tabular}
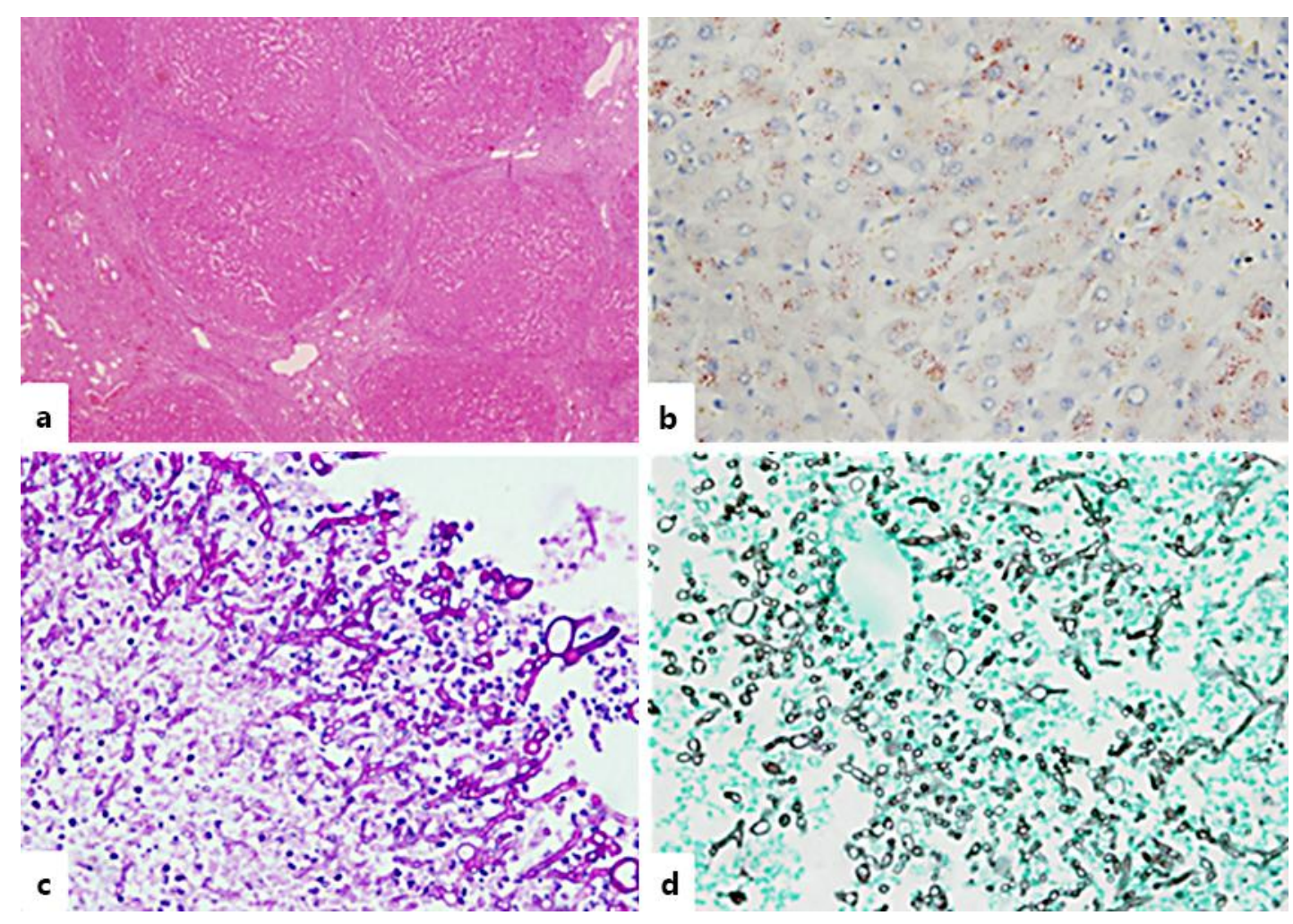

Fig. 2. a Explanted cirrhotic liver. H\&E, $\times 40$. $b$ Explanted liver with multiple copper deposits. Copper, $\times 40$. c, d Brain abscess, PAS-D, $\times 40$ (c) and Gomori, $\times 40$ (d), presenting formations morphologically consistent with Aspergillus spp. 